\title{
Mujer, género, educación, servicio social y ocupaciones. Un atisbo a la historia de las ocupaciones femeninas 1955-1969
}

\author{
Woman, gender, education, social service and occupations \\ An observation to the history of feminine occupations \\ 1955-1969
}

\author{
Karol Vanessa Martínez Naranjo ${ }^{1}$ \\ Estefanía Vergara Buriticá2
}

Recibido: 7 de diciembre 2016 • Enviado para modificación: 2 de enero de 2017 • Aceptado: 2 de febrero de 2017

Martínez, K., \& Vergara, E. (2016). Mujer, género, educación, servicio social y ocupaciones. Un atisbo a la historia de las ocupaciones femeninas 1955-1969. Revista Ocupación Humana, 16 (2), 68-80.

\begin{abstract}
Resumen: Los acontecimientos históricos entre las décadas del cincuenta y sesenta del siglo XX provocaron una serie de condiciones sociopolíticas y culturales que hicieron posible un mayor ingreso de la mujer a la educación, que si bien promulgaba aires modernistas, en la práctica seguía reproduciendo patrones culturales ortodoxos asignados tradicionalmente a su sexo, como el de esposa y madre. No obstante, el transcurrir de los años traería consigo fuertes cambios, produciendo con ello la modificación progresiva de las nociones de ser mujer en la sociedad colombiana. Aquí se refieren, desde una perspectiva de género, las diversas ocupaciones y opciones educativas a las que atendieron las mujeres de estos decenios, principalmente en Santiago de Cali, además de resaltar el papel relevante del género femenino, de acuerdo con un ideal mariano y piadoso, en la implementación de organizaciones de servicio social y educación que velaban por el bienestar de los desamparados.
\end{abstract}

Palabras clave: Historia, mujer, género, servicio social, educación de la mujer.

Abstract: Historical events between the 1950s and 1960s in the XX century brought about a series of socio-political and cultural conditions that made possible a greater access of women to education, which, although promulgating a modernist attitude, in practice continued reproducing the conventional cultural patterns traditionally assigned to gender, such as that of wife and mother. Nevertheless, the passing of the years would bring strong changes, producing a progressive change in the notions of being a woman in the Colombian society. This article covers, form a gender perspective, the various occupations and educational options that the women of Santiago de Cali had in those times; also highlighting the relevant role of the female, according to a Marian and pious ideal, in the implementation of social service and education institutions that looked after the welfare of the homeless.

Keywords: History, woman, gender, social service, women's education.

\footnotetext{
${ }^{1}$ Licenciada en Historia, Universidad del Valle. Santiago de Cali, Colombia. karol.martinez@correounivalle. edu.co

${ }^{2}$ Licenciada en Historia. Docente de cátedra. Universidad del Valle. Santiago de Cali, Colombia. estefania. vergara@correounivalle.edu.co
} 


\section{Introducción}

Colombia presentó durante el siglo $X X$ una metamorfosis sin precedentes debido a su reciente inserción en lo que significaba la modernidad; no obstante, no sería sino hasta pasada la segunda mitad del siglo que las gentes de la nación percibirían verdaderos cambios, debido a que en la década del sesenta se gestaron impetuosos progresos y revoluciones que producirían la conjunción de circunstancias necesarias para marcar un nuevo horizonte en la historia mundial y particularmente en la del país.

Aunque es cierto que el desarrollo material de las ciudades avanzaba notoriamente, no sucedía lo mismo con los imaginarios de sus habitantes; si bien nadie discutía que las ciudades tenían que cambiar, no se opinaba lo mismo con relación a la modificación de los roles imperantes que definían el ser hombre y mujer, los cuales, en su forma más ortodoxa, seguían reproduciendo arquetipos arcaicos.

En este orden de ideas, en la sociedad colombiana empezaron a presentarse discrepancias frente al rol que debía cumplir la mujer, el cual se disputaba entre las nociones tradicionales y las más progresistas, siendo así, las representaciones que se difundían en torno a la mujer empezaron a ser contradictorias; ahora ellas debían conservar su feminidad, pero también demostrar la fuerza necesaria para restaurar la de- mocracia, maltrecha debido a la crisis moral que dejó la época de la Violen$\mathrm{cia}^{3}$ y asimismo hacer frente a todos los impases que se pudieran presentar.

Puestas estas cartas sobre la mesa, las mujeres se hicieron con las mejores posibilidades, accediendo a una variedad de ocupaciones y estudios, los cuales serán tema principal de este documento por la importancia que implica para el desarrollo holístico femenino. Así pues, este estudio emprende la empresa de reflexionar sobre el desarrollo del contexto y las posibilidades en las que se desenvolvió la mujer en los años cincuenta y sesenta a partir de una revisión y análisis exhaustivo de bibliografía y artículos de los diarios Relator y El País, los cuales abarcan su representación y desarrollo en la sociedad colombiana, vallecaucana y sobre todo caleña. Aunque estos diarios ilustran sobre todo la concepción de mujer de la élite, también se encuentran en ellos representaciones de la mujer de clase media y baja.

En este texto se estudiaron los discursos sobre la experiencia, más que las experiencias mismas, pues se trabaja desde el ideal de la Nueva Historia Cultural que "pone su énfasis en los modos de 'representación' y en la construcción cultural/discursiva de identidades, etc., que reflejan un sesgo lingüístico" (Weinstein, 2000, p. 76-77). Estructuralmente este escrito se divide así: primero se trabaja acerca

\footnotetext{
${ }^{3}$ La Violencia hace referencia a un periodo histórico colombiano comprendido entre finales de los años cuarenta y principios de los cincuenta durante el cual se presentaron conflictos políticos bipartidistas entre los ciudadanos de filiación liberal o conservadora, época raíz de la cual surgieron figuras populares que infundieron terror en la nación, como la "policía chulavita" en Boyacá, los "pájaros" en el centro del país, y por último, los "bandoleros", figura alegórica a una especie de héroe guerrillero defensor de los campesinos.
} 
del papel de la mujer como categoría representativa desde la perspectiva de género, que cuestiona los fundamentos asignados al "deber ser" de acuerdo al sexo, en instituciones como la Iglesia, la educación y el Estado; luego se describe el contexto histórico de Cali durante las décadas de 1950 a 1960, para poder entrar a situar a la mujer en sociedad; después se trabaja el tema de las opciones educativas y ocupaciones de la mujer de acuerdo a la clase social; para terminar se presentan algunas conclusiones.

Como es posible evidenciar, Colombia gestó un sinfín de transformaciones sociales, económicas y culturales que sugestionaron los primeros pasos de la incursión masiva de la mujer en la educación básica y superior ${ }^{4}$. En tanto es durante ese periodo cuando se inicia la formación y la práctica en Terapia Ocupacional en Colombia, este artículo busca además aportar elementos de contexto para la comprensión histórica de tales hechos.

\section{La mujer en Santiago de Cali desde la historia de género}

El marco teórico de este documento se desarrolla a partir de una perspectiva de género, en donde los sujetos sociales constituyen construcciones culturales mediante la continua resignificación de la experiencia colectiva. Es así como la mujer de Occidente ha adquirido un rol de inferioridad, debido a instituciones de control social como la Iglesia, la familia patriarcal, el Estado y las escuelas, que le han asignado, desde siglos atrás ${ }^{5}$, características de sacrificio y humildad como dones propios de su sexo. Esto resulta visible aún para los años analizados en esta publicación, pues los actores que desarrollan los roles hegemónicos de género supeditan el accionar femenino al mero acompañamiento de la función masculina, otorgándole prohibiciones políticas y justificando su accionar como producto de un orden universal.

Desde una visión de la Historia Universal, para algunos exponentes de la filosofía griega y medieval, como Aristóteles y Santo Tomás, la vida de las mujeres rondaba alrededor de la única misión de contribuir en la realización del hombre, prolongar la especie y cuidar del hogar. Su existencia por sí sola no tenía ninguna razón de ser, puesto que "la mujer es mujer en virtud de cierta falta de cualidades - decía Aristóteles-. Y debemos considerar el carácter de las mujeres como adoleciente de una imperfección natural. Y, a continuación, Santo Tomás decreta que la mujer es un «hombre fallido», un ser «ocasional»" (De Beauvoir, 1977, p. 4).

En el caso de las religiones abrahamicas, se culpa a la primera represen-

\footnotetext{
${ }^{4}$ Parte de los planteamientos expuestos aquí surgieron de la construcción del trabajo de grado La Sexualidad Bajo la Custodia de lo Moral. Ética Sexual, Sexualidad y Mujer en las Representaciones Escritas en Cali - 19551969 (Martínez \& Vergara, 2016), por lo que se hará mención de temáticas y sustentaciones disponibles más ampliamente en aquella investigación.

${ }^{5}$ Para comprender un poco más el tema de las instituciones de control social se recomienda leer al autor Michel Foucault en su obra Historia de la Sexualidad, que consta de tres volúmenes. Aunque no trabaja directamente la historia de la mujer, hace continua referencia a su situación en la sociedad griega y medieval, sobre todo en el tercer volumen La inquietud de sí.
} 
tante del género femenino del pecado original, el cual debe ser expiado a través de la maternidad, que la relega al ámbito doméstico y a la sumisión, es así como en la biblia se afirman ideas del Apóstol Pablo como: "que las mujeres escuchen la instrucción en silencio, con todo respeto. No permito que ellas enseñen, ni que pretendan imponer su autoridad sobre el marido: al contrario, que permanezcan calladas". (1 Tm 2, 11-12 Versión Vaticano).

La educación, que a través de los siglos ha sido considerada como la llave que conduce a la superación de los pueblos, contribuyó de manera directa a consolidar estos postulados, pues transmitió un ideal de mujer tradicional mariana y sumisa, orientado únicamente a su papel de madre, consorte y ama de casa; esto lo hizo por medio de los manuales de conducta escolares católicos, como el de Manuel Carreño, que data del siglo XIX y define las relaciones entre los sexos de acuerdo a las "funciones naturales" de cada uno; siendo así,

El hombre debe comportarse como varón, no debe ser delicado pero si elegante y cortés; de otro lado, a la mujer se le define como un ser bello por naturaleza, pero como la naturaleza no la conduce para comportarse en sociedad desde su nacimiento, esta debe instruirse a través de la religión, cultivando en ella el pudor y la inocencia (Carreño, 1964, p. 32),

que le harán atractiva, pura y adecuada para el hombre.

Aún para 1959 en Cali persistían ideales tan androcéntricos en la opinión pública, que exponían que la presencia de la mujer en la política era una monstruosidad, pues según ellos:

Dios hizo a la mujer con fines muy sublimes para hacer feliz a la humanidad, ya en el hogar, en el aula, en los hospitales, en la oficina y en mil sitios que le corresponde actuar (...) La mujer en la política es funesta y se desvía de su fin para el que fue creada y se corrompe de tal manera que el marido y los hijos le huyen... (Otoya, 20 de junio de 1959, p. 1).

La década de los sesenta trae consigo otros matices en donde la mujer encuentra mayor protagonismo, pero no solo como objeto, sino como sujeto de construcción social. Empieza a apropiarse de su cuerpo, exhibiéndolo a través de la minifalda, decidiendo sobre él por medio del control natal, y eligiendo con quien establecer vínculos parentales, por medio del divorcio. Sin embargo, a pesar de todos estos visos progresistas, aún era prioridad que la mujer no perdiera su feminidad, ya que ella "nunca dejará de ser la flor perfumada del hogar, teniendo que soportar con cariño y renunciación, todos los inconvenientes de la profesión adoptada y armonizarlos con sus deberes de esposa y madre. Pero así, en adelante, será mayor su actuación" (Martha, 15 de diciembre de 1967, p. 12).

\section{Contexto histórico: transformaciones en la participación femenina en sociedad}

La década de 1950 trajo consigo grandes cambios económicos en el país, ello gracias a la bonanza económica producto del abarcamiento de los 
mercados desatendidos que dejó la Segunda Guerra Mundial. Así pues, el país vivió un aumento en la agroexportación cafetera, la industrialización y la escalonada urbanización de las ciudades capitales. Empero, no ocurrió lo mismo con los imaginarios, los cuales debieron transformarse a pequeños pasos, que ya venían dándose desde la inserción de la mujer en la vida pública del país a través del sufragio ratificado en 1954 por el General Gustavo Rojas Pinilla 6 y ejercido en el plebiscito de 1957 en el Frente Nacional.

Las diferentes percepciones que elaboran los sujetos de la sociedad de Santiago de Cali en la década del cincuenta en los medios de difusión reafirman y confirman las nociones políticas de un país; además, ratifican los roles de género y la participación en las relaciones públicas y privadas "adiestrando a las niñas para actividades domésticas y a los niños para el dominio de lo público" (Bonilla, 2012, p. 98). De esta manera, la mujer fue adquiriendo tintes que la definían como siempre bella, carismática, sumisa.

Sin embargo, con el arribo de la modernidad y las pretensiones de los nuevos gobiernos de encarrilarse en el desarrollo mundial, las concepciones estáticas de los roles de género se desestabilizan, modificándose parte de lo entendido como funciones naturales del sexo femenino. Así la mujer empieza a tener más espacio en las relaciones públicas. Ejemplo de esto a nivel nacional y departamental fueron las señoras Esmeralda Arboleda, elegida como miembro de la Asamblea Nacional Constituyente (ANAC) en 1954 y senadora del Valle del Cauca en 1958, quien fue la primera mujer en el Congreso de Colombia, y Josefina Valencia de Hubach, miembro de la ANAC en 1954, primera gobernadora del Cauca en 1955, ministra de educación (1956-1957), embajadora de la UNESCO (1957-1958) y senadora de la Alianza Nacional Popular en los años sesenta.

Acerca del papel de Josefina Valencia de Hubach y Esmeralda Arboleda como representantes políticas, se afirmaba en el Diario Relator:

La verdad es que las dos señoras elegidas en la Asamblea Nacional constituyente han probado, (...) que se puede cumplir con todos los deberes, los de la casa y los que impone un cargo de orden público. Ahora esta teoría, que dejó de serlo para convertirse en práctica, va a tener una demostración de mayor fuerza con la presencia de Josefina Valencia en la gobernación del Cauca. Creo sinceramente, y al creerlo no quiero herir susceptibilidades masculinas, que ella logrará para su región lo que ninguno de sus antecesores ha logrado (...). (Suárez de Zawadzky, 27 de octubre de 1955, p. 4).

\footnotetext{
${ }^{6}$ El presidente Gustavo Rojas Pinilla fue apoyado con fuerza por las mujeres colombianas durante su gobierno, ya que en ese entonces fue cuando se permitió que la mujer ejerciera el sufragio. De esta manera, periodistas como la destacada Clara Inés de Zawadsky celebraba el accionar del mandatario, pues éste "decidió darle impulso a la idea de que las mujeres debían tener directa y responsable participación en el manejo del Estado. (...) rompió la sostenida tradición, defendida por algunos con criterio romántico, de que la mujer solamente servía para el cuidado y dirección del hogar (...)" (Suárez de Zawadzky, 27 de octubre de 1955, p. 4). Lo anterior, refleja cambios en la concepción de la participación ciudadana femenina.
} 
Por su parte, el contexto de los años sesenta estuvo marcado por el intervencionismo norteamericano en Latinoamérica, que influyó en todos los ámbitos de la vida ya que las modas internacionales capitalistas influenciaron a las masas urbanas. En la Conferencia de Punta del Este (1961) se pactó el compromiso de ejecutar acciones para "impedir la extensión de la revolución cubana (...). Jhon F. Kennedy creó varios organismos (...), como el programa de la Alianza para el Progreso y los Cuerpos de Paz, los que tuvieron su influencia en las políticas educativas" (Helg, 1989, p. 138). Adicional a ello, los movimientos juveniles influenciados por corrientes culturales como el nadaísmo, el rock, el hippismo, la revolución sexual y la segunda oleada del feminismo, alimentaron el desarrollo de debates mundiales sobre el control natal y los anticonceptivos, el aborto, la prostitución, el matrimonio y el divorcio civil, haciendo temblar fundamentos filosóficos de religiones poderosas como el catolicismo.

\section{Educación y ocupaciones de la mujer caleña 1955-1969}

Desde 1954 las mujeres, que hasta entonces transitaban en un segundo plano político, empezaron a participar en la vida civil nacional. Para este momento la feminidad se hizo tan trascendental en lo político que el eslogan de las campañas resaltaba que cualidades como el amor, la comprensión y la tolerancia, propias de la mujer, sal- varían al país de la crisis que se avecinaba (Fajardo, 24 de mayo de 1959).

Con tal responsabilidad sobre sus hombros, las féminas se fueron encontrando con nuevos focos de preocupación, entre los que destacan la educación de sus congéneres, el derrocar las leyes que reafirmaban su dependencia conyugal, combatir los problemas morales, defender la infancia e incentivar la educación de las masas. No obstante, algunas de las instituciones educativas seguían empecinadas en mantenerse inmutables, por ello seguían concibiendo que solo debían "proporcionarle posibilidades de formación sin disolver la familia ni desnaturalizar la misión tradicional de la mujer" (Helg, 1989, p. 131), continuando así con el ideal de la reina del hogar.

Frente a estas posibilidades y bajo el telón de fondo del panorama político del Frente Nacional, muchas mujeres colombianas, sobre todo aquellas relacionadas con familias oligarcas o integrantes de comunidades religiosas, optaron por ejercer labores de servicio social que consistieron en el tratamiento educacional como alternativa de reintegración para las personas de bajos recursos, brindando especial atención a las mujeres y niños. Este servicio social se regía bajo los supuestos de la ética del cuidado $^{7}$ y era reforzado por las representaciones que imperaban alrededor de las ocupaciones que debían desempeñar aquellas

\footnotetext{
${ }^{7}$ La ética del cuidado, concepto acuñado por Carol Gilligan con base en los planteamientos de Emmanuel Kant, estaba basada en la concepción de dos tipos de ética, una de la justicia y otra del cuidado. La ética de la justicia se relacionaba con el género masculino y la del cuidado con el femenino, por lo cual se entiende como ética del cuidado aquella basada en las cualidades de la empatía, la compasión, la simpatía, la solidaridad, que sensibilizan al sujeto dándole equilibrio (Heinz, 2004).
} 
mujeres que querían ser vistas como ejemplo social, entre las que destacaban las primeras damas, las monjas, las reinas de belleza y las señoras de élite. Es así como en las noticias de la época es común encontrar que estas damas participaran como voluntarias en entidades como el Hospital Universitario del Valle (Relator, 5 de mayo de 1958), así lo muestra el encabezado de la noticia en la figura 1 .

Figura 1. Labor social como voluntarias realizan varias damas caleñas.

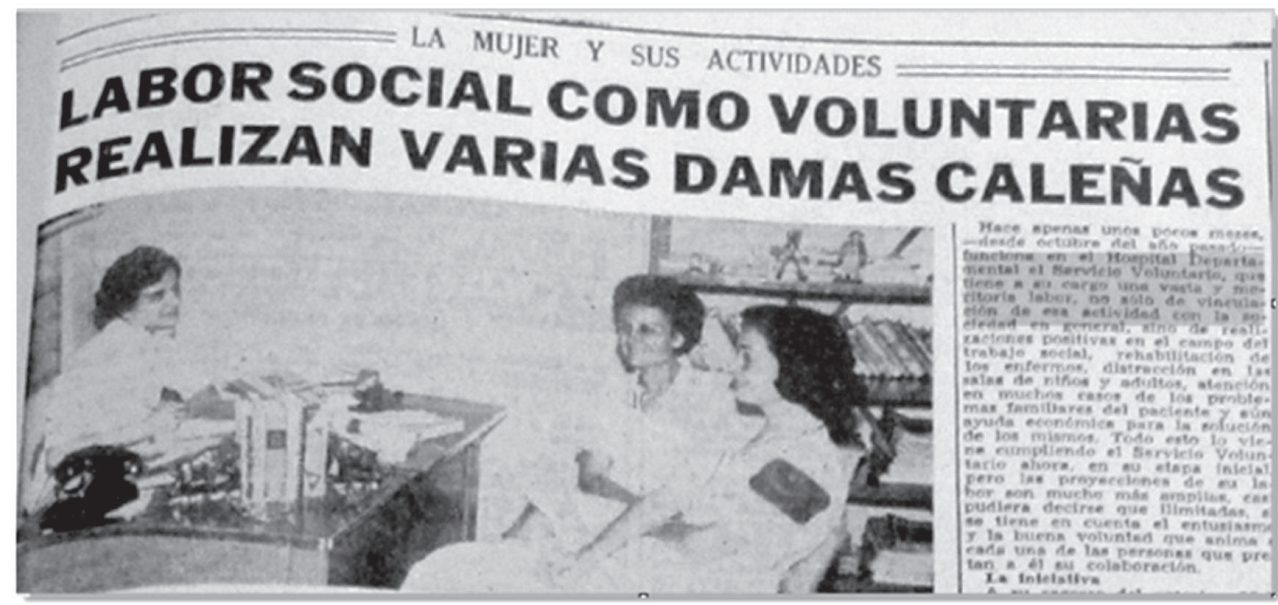

Fuente: Relator (5 de mayo de 1958, p. 9).

Con relación a lo anterior puede afirmarse entonces que las damas de clase alta debían desempeñar una doble función, esto es, ser buenas esposas y madres, y además, reflejar la mejor parte de la sociedad destacando en la beneficencia; así:

Las mujeres de las élites urbanas no solo debían cumplir estas tareas en sus propios hogares, sino que debían convertirse en una especie de misioneras sociales que se encargaran de moralizar a las mujeres y a los niños de los sectores pobres (Reyes, 1 de agosto de 1995).

Era tan fundamental en la vida de una mujer el hecho de participar de la caridad, que incluso en la nación llegó a promocionarse el Servicio Social Obligatorio femenino. Esta iniciativa finalmente no tuvo éxito, pues si bien para las mujeres de clase alta era posible prestar ese servicio, no sucedía lo mismo con el resto, porque estas debían trabajar para colaborar en el sostenimiento familiar (López, 17 de mayo de 1968).

La educación de la mujer se convirtió en unos de los principales focos de atención en el plano nacional, visto como una necesidad debido a que las féminas abarcaban gran parte de la masa analfabeta nacional. Sin embargo, la inclusión educativa no fue la misma en todos los niveles, puesto que para 1951, aunque la proporción 
de hombres y mujeres que estudiaron la primaria fue similar, a partir de la secundaria, y sobre todo en la educación superior, resalta la diferencia entre lo elegido por los géneros. Así, según los datos estadísticos de los censos poblacionales de 1951 y 1964 del
Departamento Administrativo Nacional de Estadística - DANE, la mayoría de hombres que accedieron a estudios superiores escogieron la universidad, mientras las mujeres optaron por carreras de otro nivel (Tabla 1 ).

Tabla 1. Población según grado educativo por grupos de edad y sexo.

Departamento del Valle. 1951 y 1964.

\begin{tabular}{|c|c|c|c|c|c|c|c|c|c|}
\hline \multirow[b]{2}{*}{ Año } & \multirow[b]{2}{*}{ Lugar } & \multicolumn{2}{|c|}{$\begin{array}{l}\text { Primaria } \\
(5 \text { años) }\end{array}$} & \multicolumn{2}{|c|}{$\begin{array}{l}\text { Secundaria } \\
\text { (6 años) }\end{array}$} & \multicolumn{2}{|c|}{$\begin{array}{l}\text { Universitaria } \\
\qquad(6 \text { años })\end{array}$} & \multicolumn{2}{|c|}{$\begin{array}{c}\text { Otros estudios } \\
\text { (normalistas, } \\
\text { comerciantes, artes } \\
\text { y oficios industriales, } \\
\text { técnicos, etc.) }\end{array}$} \\
\hline & & Hombres & Mujeres & Hombres & Mujeres & Hombres & Mujeres & Hombres & Mujeres \\
\hline \multirow[t]{2}{*}{1951} & $\begin{array}{l}\text { Valle del Cauca } \\
\text { (Cabeceras) }\end{array}$ & 261.234 & 247.443 & 30.112 & 23.202 & 3.373 & 441 & 3.266 & 3.738 \\
\hline & Cali (Cabecera) & $x$ & $x$ & $x$ & $x$ & $x$ & $x$ & $x$ & $x$ \\
\hline \multirow[t]{2}{*}{1964} & $\begin{array}{l}\text { Valle del Cauca } \\
\text { (Cabeceras) }\end{array}$ & 297.827 & 346.922 & 64.233 & 46.449 & 8.302 & 1.671 & 7.631 & 20.739 \\
\hline & Cali (Cabecera) & 149.111 & 179.726 & 38.482 & 28.252 & 6.074 & 1.304 & 4.854 & 12.854 \\
\hline
\end{tabular}

Fuente: Martínez \& Vergara, 2016, p. 122.

En cuanto a educación superior, en total "en el año de 1938 egresaron de las universidades colombianas 278 hombres y 6 mujeres; (...) en 1950, 737 varones y 128 mujeres. Hasta el año de 1965 (...) 2.784 hombres y 915 mujeres" (Velásquez, M. 1989, p. 30). En la Universidad del Valle de Cali, para 1964 se graduaron 26 mujeres, cuatro de Medicina, dos de Ingeniería Química, una de Técnicas de Laboratorio Químico, catorce de Técnicas de Laboratorio Médico, dos de Arquitectura, dos de Magíster en Planeamiento y una de Economía Agrícola (El País, 26 de junio de 1964). Ya para 1968 su lugar dentro de la Universidad del Valle aumentó, pues dentro de los 357 títulos otorgados 124 fueron para damas, destacándose la presencia de siete religiosas y veinticinco casadas; dentro de las graduadas resaltan cua- tro en Medicina, tres en Filosofía y una como magíster en Administración Industrial (El País. 18 de junio de 1968).

A este punto es relevante señalar que en los años sesenta la educación fue uno de los sectores que más cambios gestó, pues se hizo énfasis en fomentar el acceso para toda la población. A pesar de ello, en los censos poblacionales a nivel nacional las damas continuaban siendo mayoría en las estadísticas de analfabetismo, entre "1951 y 1964, las mujeres fueron mayoría dentro del grupo de analfabetas, que constituían el (...) 52\% y el 53\%, respectivamente. En el grupo de alfabetas eran el 49\%, (...) en 1951, y el $51 \%$ en 1964" (Velásquez, 1989, p. 27). Lo mismo ocurría en el Departamento del Valle y la ciudad de Santiago de Cali (Tabla 2), a pesar de 
tratarse de una de las ciudades principales del país terminó saturada con las migraciones campesinas que provocó la Violencia para los años cincuenta, lo que dificultó el acceso de cupos para la educación básica, sobre todo en el género femenino.

Tabla 2. Población mayor de 7 años alfabeta y analfabeta. Valle del Cauca y Cali. 1951 y 1964.

\begin{tabular}{|c|c|c|c|c|c|}
\hline \multirow{2}{*}{ Año } & \multirow{2}{*}{ Lugar } & \multicolumn{2}{|c|}{ Alfabetos } & \multicolumn{2}{|c|}{ Analfabetos } \\
\hline & & Hombres & Mujeres & Hombres & Mujeres \\
\hline \multirow[t]{2}{*}{1951} & $\begin{array}{c}\text { Valle del Cauca } \\
\text { (Cabeceras) }\end{array}$ & 171.458 & 183.078 & 36.656 & 50.900 \\
\hline & Cali (Cabecera) & 81.365 & 86.809 & 11.079 & 17.601 \\
\hline \multirow[t]{2}{*}{1964} & $\begin{array}{l}\text { Valle del Cauca } \\
\text { (Cabeceras) }\end{array}$ & 375.758 & 413.704 & 65.343 & 88.974 \\
\hline & Cali (Cabecera) & 197.225 & 220.946 & 23.885 & 37.033 \\
\hline
\end{tabular}

Fuente: Martínez \& Vergara, 2016, p. 121.

Para el decenio de 1960, las principales alternativas de estudio posterior a la secundaria que tuvo la mujer de élite en Cali, aparte de ingresar a la universidad, incluían estudiar en el país o en el exterior programas de economía doméstica o cultura general, con el objetivo principal de, al terminar su etapa académica, más que trabajar, lograr contraer matrimonio con un profesional de igual o mejor clase social.

En el caso de las hijas de la clase media, estas elegían opciones como el Colegio Universitario Femenino del Sagrado Corazón de Jesús de Cali para bachilleres y normalistas, al finalizar los estudios podían empezar un ciclo universitario o ejercer como profesoras (El País, 21 de mayo de 1965). Quienes no habían terminado su ba- chillerato optaban por cursos variados en principios de contabilidad, sociología, mecano taquigrafía ${ }^{8}$, dietética y nutrición, primeros auxilios, puericultura y derecho familiar (El País,14 de junio de 1967). De igual forma para estas damas estaban las opciones de estudiar en entidades como la Normal Femenina de Cali (El País, 26 de mayo de 1965, p. 11) y el Instituto Social de la Mujer, creado en 1963 (El País, 23 de enero de 1969, p. 10), en el cual dictaban cursos para el hogar, secretariado y clases de orientación.

Para las señoritas de las clases populares estaban las opciones de emplearse como obreras, establecerse como trabajadoras independientes en oficios como el de modista o acudir a la educación de las escuelas nocturnas, don-

\footnotetext{
${ }^{8}$ La mecanotaquigrafía, contabilidad, entre otras habilidades propias de las secretarias fueron enseñadas en las Escuelas de Comercio. El acceso popular de la mujer a ellas se debe a la industrialización nacional, que demandaba la necesidad de mano de obra especializada en estos conocimientos, además del hecho que "la educación comercial duraba aproximadamente dos años, ( ) y no exigía el curso de la primaria completa para el ingreso, una ventaja para las mujeres que no habían culminado su formación en esta etapa" (Velásquez, 1989, p. 26-27).
} 
de cursaban clases de lectura, escritura, matemáticas, sociales, moral, y religión (Relator, 25 de febrero de 1956). Podían acudir a la educación de beneficencia en entidades de servicio social y rehabilitatorio, como el centro penitenciario El Buen Pastor, donde se les brindaban orientación moral y educación pragmática (Margoth, 17 de enero de 1958), esto era, según la época, cocinar y coser. También estaban entidades direccionadas por señoras y señoritas de la alta sociedad y religiosas, como El Amparo del Gamín (Relator, 24 de octubre de 1958), la Fundación Pío X (Relator, 16 de noviembre de 1958) y la Escuela Superior para niñas (El País, 26 de marzo de 1956), de las religiosas del Colegio María Auxiliadora, con el objetivo de alejar a los infantes del camino de la "gaminería" y la prostitución, formando hombres decentes y esposas virtuosas.
En línea con lo anterior, en aras de ocupar el lugar que para la época se consideraba oportuno y eficaz para la mujer se promovieron dentro de la sociedad con gran ímpetu las carreras de servicio social, sobre todo en la segunda mitad de los años cincuenta y comienzos de los sesenta. Así se popularizaron oficios como la Enfermería y la docencia, sobre todo en la clase media, que resultaban ser parte de los máximos exponentes de las profesiones femeninas, puesto que acoplaban con eficacia las representaciones tradicionales con las más progresistas, al punto de considerarse que "ser buena esposa es de por sí una profesión que exige las cualidades que distinguen al diplomático, a la mujer de negocios, a la buena cocinera, a la enfermera, a la maestra" (Relator, 4 de noviembre de 1955).

Figura 2. Enfermería es femenina por excelencia y recompensa su abnegación.
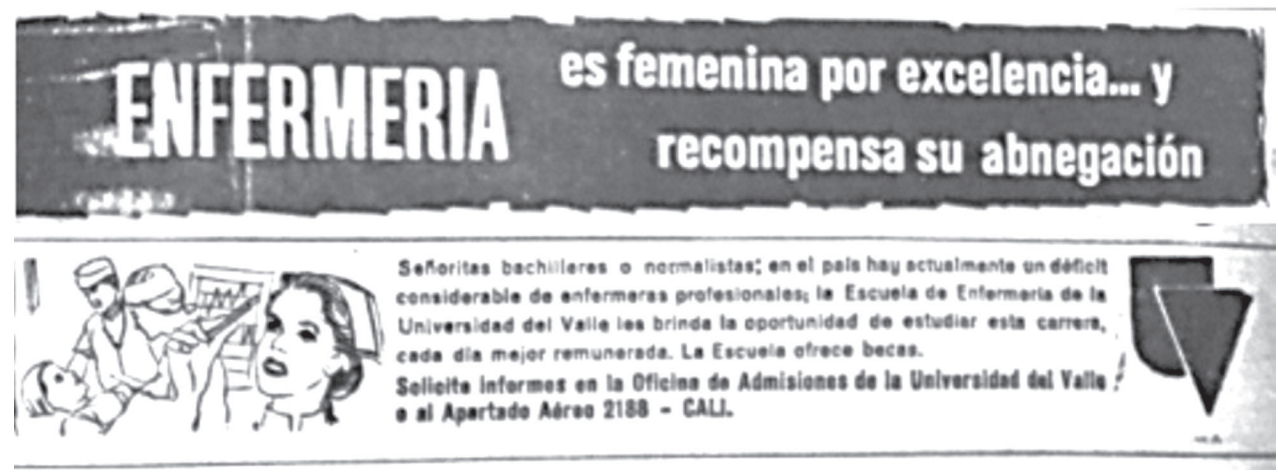

Fuente: El País. (28 de Junio de 1964, p. 3).

La profesión de Enfermería empezó a popularizarse en la sociedad colombiana, pero no en la escala en que esta lo necesitaba. Para 1957 la Escuela de Enfermeras de la Universidad del Valle ${ }^{9}$ no había logrado satisfacer

\footnotetext{
${ }^{9}$ La Escuela de Enfermería de la Universidad del Valle fue creada el 13 de octubre de 1952, mientras que "en 1937 se creó en Bogotá la primera escuela de servicio social que vinculó mujeres a la acción social como enfermería” (Hamón, 2007, p. 193).
} 
la demanda para el Hospital Departamental Universitario y en los diarios se afirmó: "solo hay 700 enfermeras graduadas en Colombia y se necesitan unas 20 mil, cada vez hay menos, el déficit se debe en gran parte porque las señoritas que terminan el bachillerato prefieren el matrimonio a iniciar una carrera universitaria" (Relator, 2 de marzo de 1957, p. 3). Esta situación cultural se veía agravada en muchos casos por el componente económico, ya que no todas las mujeres podían darse el lujo de estudiar, fue por ello que

En vista de la necesidad que tiene el país de enfermeras profesionales orientadas hacia la acción social que presten su cooperación en las campañas asistenciales, la Cruz Roja Nacional Colombiana apoyada por el Gobierno Nacional ha creído conveniente la intensificación de esta profesión y para el efecto ha concebido un número crecido de becas para varios departamentos de Colombia entre los que figura el departamento del Valle, al cual se le han asignado diez, para las mujeres que tengan interés en realizar estudios técnicos de tres años en la Escuela de Enfermeras de Bogotá. (El País, 24 de enero de 1956, p. 2).

Con respecto a la docencia, durante la década de 1950 el magisterio sufrió descalificación y desprestigio, pues no se necesitaba estar muy preparado para ejercerla; ello bajó de nivel a la profesión y se convirtió en una de las causas contextuales del ingreso femenino a la misma.

Como puede verse, las mujeres elegían su profesión, más que por gusto personal, pensando en un oficio que les permitiera ascender en la escala social dándoles prestigio, en la medida que su sexo y clase se los permitiese; es decir, se trataba de gustos de libertad o de lujo y de gustos de necesidad, trabajados por Bourdieu ${ }^{10}$ (1988).

\section{Conclusiones}

Al analizar el ideal del deber ser femenino en la época se muestra como la mujer continuó interiorizando como propias esas conductas que le eran impuestas socialmente y que le ceñían las cualidades piadosas para ser una buena hija, esposa o madre. Por ello era tan común encontrar que las mujeres entraran en colectivos para ayudar a los desfavorecidos, donde el fundamento de la espiritualidad se alcanzaba a través de la formación moral, así como que prefirieran como desarrollo personal el matrimonio o las carreras consideradas como femeninas.

Los patrones culturales contribuyen en la determinación del accionar y los roles de género. Pese a que algunas mujeres de clase alta conseguían hacerse con el estudio de carreras profesionales ${ }^{11}$, al identificar las tasas de analfabetismo y escolaridad en los censos nacionales de población se corrobora que la mayoría de las mujeres de todas las cla-

\footnotetext{
10 "Los primeros son propios de aquellos individuos producto de unas condiciones materiales de existencia definidas por la distancia con respecto a la necesidad, por las libertades o, como a veces se dice, por las facilidades que asegura la posesión de un capital; los segundos expresan, en su propio ajustamiento, las necesidades de las que son producto" (Bourdieu, 1988, p. 177).

${ }^{11}$ Lo que puede verse en la descripción del perfil de cada novia en los anuncios matrimoniales de los medios de difusión (El País, 17 de mayo de 1968).
} 
ses sociales acudían en mayor medida al estudio de carreras o cursos cortos, más que a programas universitarios, a diferencia de los hombres.

Pese a todo esto, es importante destacar que el factor fundamental de esta reflexión es la determinación con la cual la mujer se ha hecho paso a través de los complicados senderos que le han construido las representaciones sociales tradicionalistas; así pues, la mujer ha salido triunfante en diferentes ámbitos que van desde su incursión en la política, la educación y la salud, así como también el empoderamiento sobre sí misma.

\section{Referencias}

Bourdieu, P. (1988). La distinción, criterio y bases sociales del gusto. Bogotá: Editorial Taurus.

Bonilla, G. (2012). Las Mujeres en la prensa de Cartagena de Indias 1900 - 1930. Colombia: Universidad De Cartagena.

Carreño, M. (1964). Nuevo Compendio del Manual de Urbanidad y Buenas Maneras, para el uso de las escuelas de ambos sexos. 3ra edición. Bogotá: Editorial Voluntad.

De Beauvoir, S. (1977). El Segundo Sexo. Argentina: Ediciones Siglo Veinte.

1 Tm 2, 11-12. El Libro del Pueblo de Dios. La Biblia. Versión Vaticano.Traducción Argentina, 1990. Recuperado de http:// www.vatican.va/archive/ESL0506/ PZM.HTM

El País. (24 de enero de 1956). Diez becas para enfermeras en el Valle sede la Cruz Roja. Santiago de Cali, p. 2.

El País (26 de marzo de 1956). Notable obra de las Hijas de María Auxiliadora con estudiantes pobres. Santiago de Cali, p. 5.
El País. (26 de Junio de 1964). Numeroso grupo de nuevos profesionales entrega mañana la Universidad del Valle. Santiago de Cali, p. 17.

El País. (28 de Junio de 1964). Enfermería es femenina por excelencia y recompensa su abnegación. Santiago de Cali, p. 3.

El País. (21 de mayo de 1965). Colegio Universitario Femenino. Santiago de Cali, p. 4.

El País. (26 de Mayo de 1965). Normal Femenina de Cali fue aprobada por el Ministerio. Santiago de Cali, p. 11.

El País. (14 de junio de 1967). Habla la Madre Paternot. Enseñamos a la mujer a amar a Dios para su vida y su felicidad en todos. Santiago de Cali, p. 14.

El País. (17 de mayo de 1968). Elegantes bodas se anuncian para junio en esta ciudad. Santiago de Cali, p. 13.

El País. (18 de junio de 1968). 357 títulos otorga la U. del Valle. 124 damas forman parte de la promoción gigante. Santiago de Cali, p. 7.

El País. (23 de enero de 1969). Importante labor cumple en Cali el Instituto Social de la Mujer. Santiago de Cali, p. 10.

Fajardo, H. E. (24 de mayo de 1959). La mujer en la nación. Relator. Santiago de Cali, p. 5.

Hamón, N., A. (2007). La mujer en la Universidad Pedagógica y Tecnológica de Colombia (1950-1960). Revista Apuntes del CENES, 27, (44), 183-196.

Heinz, M. (2004). Normas morales y diferencias de género. La compatibilidad entre los conceptos éticos y kantianos y feministas. En Millán de Benavides, C. \& Estrada, Á. Pensar (en) género: teoría y práctica para nuevas cartografías del cuerpo (pp. 324-325). Bogotá: Editorial Pontificia Universidad Javeriana.

Helg, A. (1989). La Educación en Colombia 1946-1957. En Á. Tirado (comp.). 
Nueva Historia de Colombia. Educación Ciencias, La Mujer, Vida Diaria. Bogotá: Planeta Colombiana.

López, B. (17 de mayo de 1968). La Explosión Demográfica en nuestro país es desmesurada': Beatriz de Cárdenas. El País. Santiago de Cali, p. 12.

Margoth. (17 de enero de 1958). Las Bodas de Plata del Buen Pastor. Una Institución Moralizadora. Extraordinaria labor correccional Cumplen las Hermanas. Relator. Santiago de Cali, p. 9.

Martha. (15 de diciembre de 1967). La mujer ante la sociedad. El País. Santiago de Cali, p. 12.

Martínez, K. \& Vergara, E. (2016). La sexualidad bajo la custodia de lo moral. Ética sexual, sexualidad y mujer en las representaciones escritas en Cali, 1955-1969 (Tesis de pregrado). Universidad del Valle, Santiago de Cali, Colombia.

Otoya, A. (20 de junio de 1959). Hay que recristianizar el País para poder salvarlo. Relator. Santiago de Cali, p. 1.

Relator. (4 de noviembre de 1955). El mejor papel de La mujer. Santiago de Cali, p. 6

Relator. (25 de febrero de 1956). Con pleno éxito funcionan en el Valle las escuelas nocturnas. Santiago de Cali, p. 12.

Relator. (2 de marzo de 1957). Escuela de enfermeras del Valle, institución modelo. Santiago de Cali, p. 3.
Relator. (5 de mayo de 1958). Labor social como voluntarias realizan varias damas caleñas. Santiago de Cali, p. 9.

Relator. (24 de octubre de 1958). El "Amparo del Gamín" se establece ahora en Cali. Prestantes Damas y Caballeros Auspician la Iniciativa. Santiago de Cali, p. 3.

Relator (16 de noviembre de 1958). Creada la Fundación Pío X. Santiago de Cali, p. 6.

Reyes, C. (1 de agosto de 1995). Cambios en la vida femenina durante la primera mitad del siglo XX. Revista Credencial Historia, (68). Recuperado de http://www. banrepcultural.org/node/73271

Suárez de Zawadzky, C. (27 de octubre de 1955). El ballet de Clara Inés. Gobierno y dependencia. Relator. Santiago de Cali, p. 4.

Velásquez, M. (1989). Condición jurídica y social de la mujer. En Á. Tirado (comp.). Nueva Historia de Colombia. Educación Ciencias, La Mujer, Vida Diaria. (pp. 9-60). Bogotá: Planeta Colombiana.

Weinstein, B. (2000). La Investigación sobre identidad y ciudadanía en Estados Unidos: de la nueva historia social a la nueva historia cultural. Revista Fronteras de la Historia, 5, 76-77. 